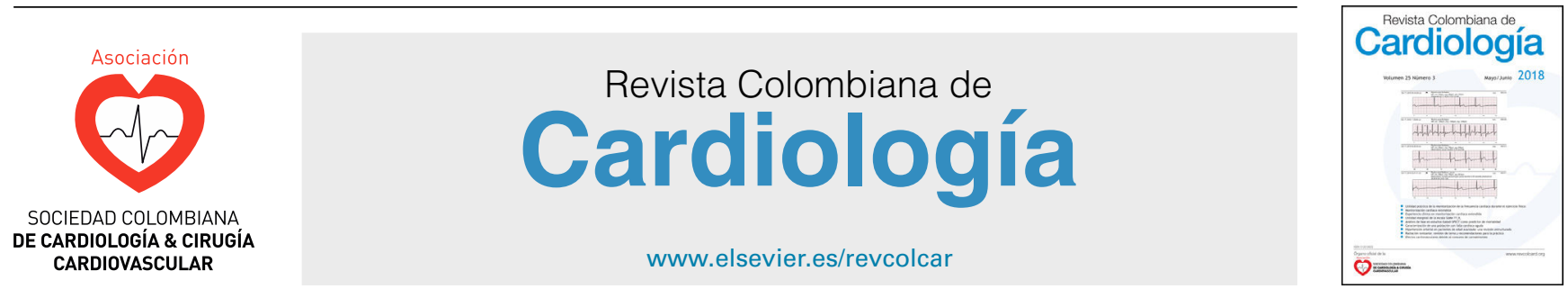

CARDIOLOGÍA DEL ADULTO - PRESENTACIÓN DE CASOS

\title{
Interferencia analítica en la determinación de troponina por anticuerpos heterófilos
}

\section{Daniel Grados-Saso ${ }^{a, *}$, Javier Escota-Villanueva ${ }^{a}$, Alba Alonso-Lorente ${ }^{b}$, María Jesús Andrés-Otero ${ }^{\mathrm{b}}$ y Carmen Lahuerta-Pueyo ${ }^{\mathrm{b}}$}

\author{
a Servicio de Cardiología, Hospital Clínico Universitario Lozano Blesa, Zaragoza, España \\ b Servicio de Bioquímica Clínica, Hospital Clínico Universitario Lozano Blesa, Zaragoza, España
}

Recibido el 8 de octubre de 2017; aceptado el 8 de julio de 2019

Disponible en Internet el 24 de octubre de 2019

\section{PALABRAS CLAVE \\ Biomarcadores; \\ Angina; \\ Anticuerpos}

\section{KEYWORDS}

Biomarkers;

Angina;

Antibodies

\begin{abstract}
Resumen Por su elevada especificidad y sensibilidad, y a raíz de la tercera definición universal de infarto estas isoformas cardiacas han sido aceptadas en el ámbito internacional como los biomarcadaores de elección en la práctica clínica para el diagnóstico de síndrome coronario agudo, preferibles a la determinación de las enzimas creatina quinasa y su isoforma $M B$. Se presenta el caso de un varón de ochenta años, quien, de manera persistente, tuvo valores elevados de troponinas, pese a evolución clínica no compatible con síndrome coronario agudo ni otras causas de elevación de este biomarcador.

(C) 2019 Sociedad Colombiana de Cardiología y Cirugía Cardiovascular. Publicado por Elsevier España, S.L.U. Este es un artículo Open Access bajo la licencia CC BY-NC-ND (http:// creativecommons.org/licenses/by-nc-nd/4.0/).
\end{abstract}

\section{Analytical interference in the determination of Troponin due to heterophile} antibodies

\begin{abstract}
Due to its elevated specificity and sensitivity, and on being the third universal definition of myocardial infarction, these cardiac isoforms have been accepted internationally as the biomarkers of choice in clinical practice for the diagnosis of acute coronary syndrome, and are preferable to the determinations of creatine kinase and its MB isoform. A case is presented on an eighty year-old man, who persistently had elevated Troponin values, despite a clinical course that was incompatible with an acute coronary syndrome or any other causes of elevation of this biomarker.

(C) 2019 Sociedad Colombiana de Cardiología y Cirugía Cardiovascular. Published by Elsevier España, S.L.U. This is an open access article under the CC BY-NC-ND license (http:// creativecommons.org/licenses/by-nc-nd/4.0/).
\end{abstract}

* Autor para correspondencia.

Correo electrónico: dgrados@salud.aragon.es (D. Grados-Saso). 


\section{Introducción}

La troponina es la proteína responsable de la regulación de la unión entre la actina y la miosina en los filamentos finos del músculo esquelético. Está formada por tres subunidades, la troponina c ( $\mathrm{TnC})$, que es el receptor del calcio y da lugar a un cambio conformacional en el complejo tropomiosinatroponina; la troponina I (Tnl), que inhibe la contracción en ausencia de calcio al unirse a la actina; y la troponina $\mathrm{T}(\mathrm{TnT})$, a través de la que se une el complejo troponina a la tropomiosina y facilita la contracción. La subunidad TnC es idéntica, tanto en el corazón como en el músculo; sin embargo, tanto la Tnl como la TnT presentan isoformas específicas de corazón, cTnl y cTnT.

\section{Caso}

Paciente de ochenta años de edad, sin alergias conocidas ni hábitos tóxicos, con antecedentes de hipertensión arterial, fibrilación auricular permanente, recambio valvular aórtico por insuficiencia aórtica severa - prótesis valvular aórtica biológica Carpentier Magna $\mathrm{n}^{\circ} 25$ - , puntaje aortocoronario de vena safena a coronaria derecha en 2008 , cardiopatía isquémica crónica - primera coronariografía en 1992 con angioplastia en coronaria derecha, y oclusión crónica de coronaria derecha y primera diagonal derecha con implante de stent en arteria descendente anterior (DA) proximal en el año 2000. En 2011 ingresó por infarto agudo de miocardio (IAM) inferior con estudio coronariográfico similar al de 2008, con permeabilidad de injerto de vena safena a coronaria derecha.

En abril de 2014 presentó IAM no Q, cardiopatía isquémica multivaso con suboclusión de ramas diagonales, no susceptibles de intervencionismo coronario percutáneo (ICP), lesiones moderadas en territorio de ramas marginales, injertos permeables y sin lesiones, y estenosis focal de descendente anterior media, la cual se trató con implante de stent convencional.

En septiembre de ese año reingresó por dolor torácico. Se le hizo coronariografía, que mostró los mismos hallazgos evidenciados en abril. En el ecocardiograma se observó moderada depresión sistólica con aneurisma inferobasal e hipocinesia septal y apical. Prótesis aórtica normofuncionante.

En noviembre ingresó nuevamente por dolor torácico en reposo irradiado a brazo izquierdo sin cortejo vegetativo asociado, de varias horas de evolución, de moderado/intenso (misma clínica que en ocasiones anteriores).

En el ECG de ingreso se evidenció fibrilación auricular con respuesta ventricular controlada, onda $\mathrm{Q}$ inferior y las mismas alteraciones de la repolarización descritas previamente (elevación de ST inferior, presente con y sin dolor). Se determinó cTnl en el autoanalizador Acces2 (Beckman Coulter inc, California, USA) obteniéndose un valor inicial de $7,8 \mathrm{ng} / \mathrm{ml}$ (valor de referencia inferior a 0,04 $\mathrm{ng} / \mathrm{ml}$ ). La seriación de biomarcadores constató persistencia de valores de troponina entre 7 y $8 \mathrm{ng} / \mathrm{ml}$, mientras que las enzimas cardíacas, creatinina quinasa (CK) y CK-MB, permanecieron normales durante todo el ingreso, sin presentar curva de necrosis.
No se registró recurrencia del dolor torácico desde el ingreso ni cambios en los ECG realizados.

Al presentar la misma clínica que en el ingreso anterior, en un primer momento se sopesó la posibilidad de trombosis protésica persistente causante de embolias coronarias que provocasen la elevación persistente de biomarcadores.

Ante la buena evolución clínica y la persistencia de la elevación mantenida de niveles de cTnl sin nuevos eventos que justificaran los valores de troponina elevados, se sospechó la posibilidad de interferencia analítica en la determinación de troponina I cardiaca, por lo que se decidió comentar el caso con el servicio de Bioquímica Clínica.

Inicialmente, para comprobar la existencia de interferencia analítica, se realizaron diluciones seriadas de la muestra sin observarse linealidad, compatible con la sospecha de interferencia, por lo que se decidió remitir muestras congeladas a un laboratorio de referencia en Marsella.

Finalmente, el laboratorio de referencia confirmó que la elevación de cTnl se debía a la presencia de anticuerpos heterófilos en el suero del paciente, por lo que esto anulaba la fiabilidad de la determinación de cTnl si previamente la muestra no es tratada con un bloqueante específico de estos anticuerpos. La cTnl fue solicitada a este paciente en analíticas posteriores, manteniéndose elevada en todos ellos; el resultado más reciente data de marzo de 2017, 3,63 ng/ml, elevación que no se presentó al analizarse la cTnThs en el autoanalizador de Roche cobas 6000 e601 (Roche Diagnostics GmbH, Mannheim, Germany, con valor de $19,73 \mathrm{ng} / \mathrm{L}$ (valor de referencia inferior a 14 $\mathrm{ng} / \mathrm{L})$.

Se ajustó tratamiento antianginoso y se procedió al alta, sin reingresos en los meses posteriores.

\section{Discusión}

El empleo de la troponina como marcador de daño miocárdico, en un contexto clínico adecuado, posee una elevada sensibilidad diagnóstica. Permite la estratificación del riesgo de eventos y el diagnóstico precoz y adecuado de varias entidades, entre las que se destaca por su importancia el síndrome coronario agudo ${ }^{1}$.

Conviene tener en cuenta que, a pesar de sus virtudes, la troponina no es infalible. Un gran número de factores pueden producir valores elevados de este marcador que reflejan el daño miocárdico real por mecanismos distintos a la aterotrombosis coronaria. Entre ellos, además de los más conocidos y frecuentes en la práctica clínica, están la insuficiencia renal, la insuficiencia cardíaca, la enfermedad pulmonar obstructiva crónica o la sepsis; y cabe destacar otros como el síndrome de takotsubo, la cardioversión eléctrica y los accidentes cerebrovasculares.

En otras situaciones menos frecuentes es posible hallar valores elevados de troponina por alteraciones propias de su determinación analítica.

Un tipo de interferencia, poco frecuente, es aquella que se da por anticuerpos frente a alguno de los componentes de los reactivos utilizados en los inmunoanálisis de troponina. Se trata de anticuerpos heterófilos endógenos humanos presentes en el suero de algunos pacientes y que son capaces de unirse a otras inmunoglobulinas. Entre ellos, los HAMA 
(anticuerpos humanos antirratón) son los más frecuentes, y son capaces de unirse con las inmunoglobulinas de ratón o con las de otras especies ${ }^{2}$. La prevalencia descrita de la presencia de anticuerpos heterófilos en la población general puede llegar al 40\% (varía entre el 0,2 y 40\%) pero el número de pacientes con títulos suficientemente elevados como para dar un resultado positivo en la determinación de troponina se estima que es bastante menor.

La amplia disponibilidad actual de biomarcadores de lesión miocárdica, como la troponina, con una elevada especificidad y sensibilidad en los servicios de Urgencias, Cardiología y unidades de críticos e intermedios podría llevar al médico a la falsa creencia de haber encontrado el marcador bioquímico infalible en el síndrome coronario agudo, si bien es verdad que al compararla con las demás opciones existentes, en el contexto clínico adecuado, la troponina presenta las mejores características.

El marcador bioquímico ideal debe poseer alta sensibilidad y especificidad, además de incrementar su valor precozmente después del cuadro clínico para facilitar un rápido diagnóstico. La amplia utilización de la medición de valores de troponina, basada fundamentalmente en procedimientos de inmunoanálisis, ha demostrado que también es sensible a interferencias que pueden disminuir su especificidad diagnóstica, por ello se recomienda que se consideren los posibles interferentes. El conocimiento de los falsos positivos y negativos en la medición de troponina es importante para evitar errores diagnósti$\cos y$ terapéuticos en el manejo del síndrome coronario agudo $^{3}$.

Ante la sospecha de encontrarse frente a un caso de elevación de troponina debido a anticuerpos heterófilos, el clínico deberá ponerse en contacto con el laboratorio clínico con el objetivo de poner en marcha los mecanismos de confirmación de esta situación. En primer lugar, se solicitarán las enzimas $C K$ y $C K M B$, si sus valores se encuentran dentro de los intervalos de referencia; se requerirá mayor estudio del suero. Para comprobar un falso positivo, a continuación se realizarán diluciones seriadas de la muestra. Si no se aprecia linealidad, la posibilidad de encontrarse ante un falso positivo es muy alta ${ }^{4}$. En tercer lugar, la muestra se puede enviar a un laboratorio externo que cuente con un inmunoanálisis diferente ${ }^{5}$. Finalmente, para la confirmación definitiva de la presencia de anticuerpos heterófilos en suero del paciente es necesario hacer un test con un agente bloqueante específico de anticuerpo $(\mathrm{HBR})^{6}$.

El tratamiento de muestras con sospecha de presencia de anticuerpos heterófilos con HBR de Santibodies Laboratory, Inc consiste en la adición de $500 \mu \mathrm{L}$ de suero o plasma sobre un pellet liofilizado, el cual está formado por una mezcla de inmunoglobulinas animales. Se homogeniza la mezcla y se incuba durante una hora a temperatura ambiente antes de realizar la medición de cTn en autoanalizador. El test es positivo si los valores recuperados de cTn se encuentran fuera del margen del $100 \pm 20 \%$ respecto a los valores sin el tratamiento previo (tabla 1). En este caso, los valores de recuperación estaban comprendidos entre el 13 y el $18 \%$, lo cual permitió afirmar que se estaba frente a un caso confirmado de presencia de anticuerpos heterófilos que interferían en la medición de cTnl en Acces2 de Beckman Coulter.
Tabla 1 Unidades: Ng/ml (nanogramos/ mililitro). Técnica: TnIA2

\begin{tabular}{lll}
\hline Description & CHU Results & Recovery \\
\hline S1, neat & 7,01 & - \\
S1 + PolyMak & 7,37 & $105 \%$ \\
S1 + HBR-1 & 0,93 & $13 \%$ \\
S1 + AP Mutein & 7,60 & $108 \%$ \\
S2, neat & 6,77 & - \\
S2 + HBR-1 & 1,04 & $15 \%$ \\
S3, neat & 7,04 & - \\
S3 + HBR-1 & 1,29 & $18 \%$ \\
S4, neat & 6,55 & - \\
S4 + HBR-1 & 0,86 & $13 \%$ \\
QC2, neat & 0,73 & - \\
QC2 + PolyMak & 0,74 & $102 \%$ \\
QC2 + HBR-1 & $0, .73$ & $100 \%$ \\
QC2 + AP Mutein & 0,76 & $104 \%$ \\
\hline
\end{tabular}

Mediciones de cTn en autoanalizador tras adición de inmunoglobulinas animales. El test es positivo si los valores recuperados de cTn se encuentran fuera del margen del $10 \pm 20 \%$ respecto a los valores sin el tratamiento previo. S1: suero 1, HBR1: heterophilic Scantibodies Blocking Reagent 1 (reactivo bloqueante especifico de anticuerpo), AP mutein: Alkaline Phosphatase Mutein (alcalina fosfatasa muteína), QC2: quality control 2 (control de calidad 2).

\section{Responsabilidades éticas}

Protección de personas y animales. Los autores declaran que para esta investigación no se han realizado experimentos en seres humanos ni en animales.

Confidencialidad de los datos. Los autores declaran que han seguido los protocolos de su centro de trabajo sobre la publicación de datos de pacientes.

Derecho a la privacidad y consentimiento informado. Los autores declaran que en este artículo no aparecen datos de pacientes.

\section{Conflicto de intereses}

Ninguno.

\section{Agradecimientos}

A los servicios de Cardiología y Bioquímica Clínica del Hospital Clínico Universitario Lozano Blesa.

A la Dra. Andrés del laboratorio de Urgencias de Bioquímica y al Dr. Escota del Servicio de Cardiología Clínica - Hospitalización.

\section{Bibliografía}

1. Lefort G, D'Antonio C, Caffery T. A non-ischaemic cause of elevated troponin. BMJ Case Rep. 2014, http://dx.doi.org/10.1136/bcr-2014-203729. 
2. Zaidi A, Cowell R. False positive cardiac troponin elevation due to heterophile antibodies: more common than we recognise? BMJ Case Rep. 2010.

3. Lippi G, Aloe R, Meschi T, Cervellin G. Interference from heterophilic antibodies in troponin testing. Case report and systematic review of the literature. Clin Chim Acta. 2013:79-84.

4. Muñoz Pérez M, García de Guadiana Romualdo L, Guillén Campuzano E, Rodríguez Fraga O, Galán Ortega A, Oliver Sáez P.
Recomendaciones para el uso de marcadores bioquímicos de necrosis miocárdica ante la sospecha de síndrome coronario agudo. Documentos de la SEQC. 2015:68-81.

5. González Hernández A. Principios de bioquímica clínica y patología molecular. 2. a ed Barcelona: ElSevier; 2014.

6. Apple FS, Collinson P. Analytical characteristics of high-sensitivity cardiac troponin assays. Clin Chem. 2012;58:54-61. 